\title{
An Anticoagulant Dermatan Sulfate Proteoglycan Circulates in the Pregnant Woman and Her Fetus
}

\author{
Maureen Andrew," Lesley Mitchell," Leslie Berry," Bosco Paes," Michael Delorme," \\ Frederick Ofosu, ${ }^{*}$ Robert Burrows, and Bashir Khambalia* \\ Departments of ${ }^{*}$ Pediatrics, ${ }^{\ddagger}$ Pathology, and ${ }^{\S}$ Obstetrics and Gynecology, McMaster University, Hamilton, Ontario, Canada L8N $3 Z 5$
}

\begin{abstract}
Investigation of the in vitro ability of plasma from pregnant women to inhibit exogenous thrombin ( $25 \mathrm{nM})$ demonstrated that heparin cofactor II inhibited more thrombin $(3.0 \pm 0.7 \mathrm{nM}$, mean \pm SD) than plasma from women 3-5 d postpartum $(1.9 \pm 0.5 \mathrm{nM})$ or plasma from nonpregnant adults $(1.5 \pm 0.4$ $\mathrm{nM})$. Levels of heparin cofactor II were only slightly increased over normal in both pregnant and postpartum women and did not account for the observed increase in thrombin bound to heparin cofactor II. Assay of pregnancy plasma for dermatan sulfate anticoagulant activity demonstrated the presence of activity equivalent to $0.23 \pm 0.02 \mu \mathrm{g} / \mathrm{ml}$ of porcine mucosal dermatan sulfate. This activity could not be demonstrated in normal adult plasma or plasma from women on the contraceptive pill. The mass of dermatan sulfate in pregnancy and umbilical cord plasmas was increased over adult control plasma by $0.20 \mu \mathrm{g} / \mathrm{ml}$ $(53 \%)$ and $0.29 \mu \mathrm{g} / \mathrm{ml}(76 \%)$, respectively. The glycosaminoglycan-containing fraction of plasma was isolated and an assay for anticoagulant dermatan sulfate confirmed its presence in both pregnancy and cord plasmas but minimal activity in adult plasma. Gel chromatography of isolated fractions from both pregnancy and cord plasmas revealed a polydisperse, active species with apparent $M_{\mathrm{r}} 150,000 \mathrm{D}$. Reductive elimination decreased the apparent $M_{\mathrm{r}}$ of the active species on gel chromatography to 31,000 D for cord and 21,000 D for pregnancy products. This confirmed the presence of an anticoagulant active dermatan sulfate proteoglycan circulating in the plasmas of pregnant women at term and fetuses at delivery. (J. Clin. Invest. 1992. 89:321-326.) Key words: glycosaminoglycan • heparin cofactor II • perinatal • thrombin
\end{abstract}

Parts of this work have previously been presented and published in abstract form: 31 st Annual Meeting of the American Society of Hematology, Atlanta, GA, December 1989 (1989. Blood. 74:97a) and 59th Annual Meeting of the Society for Pediatric Research, Anaheim, CA, April 1990 (1990. Pediatr. Res. 1990. 27:262a).

Address reprint requests to Dr. Andrew, HSC 3N27, McMaster University, 1200 Main Street West, Hamilton, Ontario, Canada L8N $3 Z 5$.

Received for publication 9 May 1991 and in revised form 24 September 1991.

J. Clin. Invest.

(c) The American Society for Clinical Investigation, Inc.

$0021-9738 / 92 / 01 / 0321 / 06 \$ 2.00$

Volume 89, January 1992, 321-326

\section{Introduction}

Pregnancy is a unique physiologic state with profound changes in the hemostatic system. Fibrinolytic activity is markedly impaired primarily resulting from increases in inhibitors of plasminogen activators (1-3). In contrast, the plasma concentrations of most procoagulants, especially fibrinogen (1), factor VIII (1), von Willebrand factor (1), and factor VII activity (4) are increased in plasmas of pregnant women. The levels of most inhibitors of coagulation are not altered or only slightly increased $(1,5-8)$ but protein $S$ is decreased (9). The net result of the altered coagulation system is that thrombin may be generated in increased amounts in normal pregnancy (10-12) compared to nonpregnant adults. The regulation of thrombin action on factors V and VIII is key to the control of coagulation (13) and, if uncontrolled, enhanced thrombin generation could lead to thrombosis. Indeed, pregnancy (including the postpartum period) has been considered to be a "hypercoagulable state" because there is an increased incidence of thromboembolic complications during this period $(14,15)$. However, during late pregnancy, the incidence of thrombosis is lower than one would predict from the altered venous hemodynamics created by the gravid uterus (16). In fact, one analysis showed there was no higher incidence of thromboembolic complications in pregnancy than in the normal population but a fivefold higher incidence in the postpartum period (17).

The hemostatic system of the fetus and newborn is in a dynamic and immature state evolving towards the adult system (18). During normal labor and delivery, there is activation of the fetal coagulation system with thrombin generation (19). Yet, healthy infants do not develop thromboembolic complications despite physiologically low levels of antithrombin III (AT III) ${ }^{1}$, heparin cofactor II (HC II), protein C, and protein S. Further, infants with inherited homozygous protein $\mathrm{C}$ deficiency are relatively protected in utero but develop life-threatening thromboembolic complications in the postpartum pe$\operatorname{riod}(20)$.

We describe herein the results of investigations into the ability of plasmas from pregnant women and fetuses to inhibit thrombin and characterization of a naturally occurring anticoagulant, the presence of which may help to explain some of the above observations.

1. Abbreviations used in this paper: AT III, antithrombin III, DS, dermatan sulfate; GAG, glycosaminoglycan; HC II, heparin cofactor II; $\alpha_{2} \mathrm{M}, \alpha_{2}$-macroglobulin. 


\section{Methods}

Porcine mucosal dermatan sulfate (DS; MF 701, Batch 48) was obtained from Mediolanum Pharmaceutici, Milan, Italy. Chondroitin $A B C$ lyase (EC 4.2.2.4) and chondroitin AC lyase (EC 4.2.2.5) were obtained from ICN Biomedicals Canada Inc., Mississauga, ON, and were reconstituted in a buffer of $0.15 \mathrm{M} \mathrm{NaCl}$ and $0.01 \mathrm{M}$ sodium acetate. Ancrod (EC 3.4.21.28) was from Connaught Laboratories, Toronto, ON. Sepharose CL-4B and Sephadex G-200 were from Pharmacia, Uppsala, Sweden, and Hyflo Super-Cel was from Fisher Scientific Co., Toronto, ON. Alcian blue $8 \mathrm{GX}$, dimethylsulfoxide, and the nonspecific protease, Pronase E (Streptomyces griseus), were purchased from Sigma Chemical Co., St. Louis, MO. Cellulose acetate strips (Sepraphore III) were from Gelman Sciences, Inc., Ann Arbor, MI. An assay for dermatan sulfate anticoagulant assay (Stachrom DS) was from Diagnostica Stago, Asnières, France. Purified human thrombin was a kind gift of Dr. J. W. Fenton II, Albany, NY. Antiserum to AT III, HC II, and $\alpha_{2}$-macroglobulin $\left(\alpha_{2} \mathrm{M}\right)$ were from Atlantic Antibodies, Scarborough, ON; Behring, Hoechst, Montreal, PQ; and DAKO (Dimension Labs), Burlington, ON, respectively.

Plasma samples. Paired blood samples were obtained, with informed consent, from 17 consecutive women with normal pregnancies within $24 \mathrm{~h}$ before elective caesarean section and 3-5 d postpartum. Blood was collected into $3.8 \%$ sodium citrate $(9: 1 \mathrm{blood} /$ citrate) and plasma obtained by centrifugation at $1,700 \mathrm{~g}$ for $15 \mathrm{~min}$. Plasmas from 16 nonpregnant adults served as control. These were used for quantitation of thrombin inhibition by SDS-PAGE (see below) and DS anticoagulant activity. Cord plasmas were obtained consecutively from healthy newborns after uncomplicated delivery. Subsequently, plasma pools from a number of groups of at least 10 individuals each (women at 6,16 , and 30 wk gestational age, pregnant women at term, women on oral contraceptive pills, nonpregnant adults, and cords) were used for DS anticoagulant assay. Assays for DS anticoagulant activity were also performed on individual samples from a separate group of 10 pregnant women, 10 women postpartum, and 10 nonpregnant adults (five women, five men). Pooled plasmas were used for purification of glycosaminoglycan (GAG) containing material (see below).

Thrombin-inhibitor complex formation. The contributions of AT III, HC II, and $\alpha_{2} \mathrm{M}$ to the inhibition of exogenous thrombin were determined as previously described (21). In brief, plasma samples were defibrinated with ancrod. In some experiments, defibrinated plasma was reacted with chondroitin $\mathrm{ABC}$ or $\mathrm{AC}$ lyase (final concentration 0.3 $\mathrm{U} / \mathrm{ml}$ ) for $1 \mathrm{~h}$ at $37^{\circ} \mathrm{C}$. Selectivity of these enzymes has been previously demonstrated (22). ${ }^{125} \mathrm{I}$-Thrombin was added to the plasma samples (final concentration $25 \mathrm{nM}$ ) and incubated at $37^{\circ} \mathrm{C}$ for $90 \mathrm{~s}$. The proportion of thrombin complexed by each inhibitor was the same at 30 , 45,60 , and $90 \mathrm{~s}$ in both pregnancy and nonpregnant adult plasmas (data not shown) and the 90-s time point was chosen for convenience. The reaction was stopped by sampling into 3 vol of SDS sample buffer ( $5 \%$ mercaptoethanol, $10 \%$ glycerol, $0.06 \mathrm{M}$ Tris- $\mathrm{HCl}, 0.01 \%$ bromophenol blue, $\mathrm{pH} \mathrm{6.8)}$ and heating in a boiling water bath for $2 \mathrm{~min}$. The samples $(\sim 10,000 \mathrm{cpm}$ per lane) were subjected to SDS-PAGE on a $4 \%$ stacking gel and $5-15 \%$ gradient running gel. Gels were stained with $0.1 \%$ Coomassie Blue R250 in $40 \%$ methanol $/ 10 \%$ acetic acid, destained in $40 \%$ methanol $10 \%$ acetic acid, and dried onto filter paper. Autoradiography was carried out and the amount of thrombin bound by each inhibitor measured by quantitative densitometric scanning. The positions of the thrombin-inhibitor complexes were determined by performing the same procedure in plasma deficient in AT III or immunodepleted of $\alpha_{2} \mathrm{M}$, or in plasma to which heparin or DS had been added. Inhibitor concentrations in plasma were measured by immunoelectrophoresis (HC II) or radial immunodiffusion (AT III, $\left.\alpha_{2} \mathrm{M}\right)$.

DS mass assay. Plasma pools were treated with chondroitin AC lyase (final concentration $0.025 \mathrm{U} / \mathrm{ml}$ ) for $5 \mathrm{~h}$ at $37^{\circ} \mathrm{C}$. Aliquots were then reacted with chondroitin $\mathrm{ABC}$ lyase (final concentration $0.05 \mathrm{U} /$ $\mathrm{ml}$ ) or an equal volume of enzyme buffer for $5 \mathrm{~h}$ at $37^{\circ} \mathrm{C}$. The resulting samples were treated with $1.0 \mathrm{mg} / \mathrm{ml}$ Pronase $\mathrm{E}$ while dialyzing against $0.1 \mathrm{M}$ Tris- $\mathrm{HCl}, 0.002 \%$ sodium azide, $\mathrm{pH} 7.5$ for $48 \mathrm{~h}$. Every $12 \mathrm{~h}$, an additional $0.5 \mathrm{mg} / \mathrm{ml}$ of protease was added to the reaction. The product was pressure dialyzed against water to a volume of $\sim 1 \mathrm{ml}$ and centrifuged $15 \mathrm{~min}$ in an Eppendorf centrifuge (Brinkmann Instruments, Westbury, NY). The supernatants were dried on cellulose polyacetate strips. The spots were stained with $0.025 \%$ alcian blue $8 \mathrm{GX} /$ $25 \%$ ethanol $/ 10 \%$ acetic acid and destained in $40 \%$ methanol $/ 10 \%$ acetic acid. Each spot was suspended in $1 \mathrm{ml}$ of dimethylsulfoxide and the absorbance measured at $678 \mathrm{~nm}$. The difference between the two absorbances (chondroitin $\mathrm{ABC}$ lyase and buffer treated) was compared to a standard curve of porcine mucosal DS of known mass concentration. Porcine mucosal DS was fully recovered when added to adult plasma and subjected to this technique. This staining technique has been shown to be sensitive and selective for staining of GAG (23).

DS anticoagulant activity assay. The ability of DS to catalyze inhibition of exogenous thrombin was determined using a modification of a commercial assay based on the method of Dupouy et al (24). In brief, fibrinogen, AT III, and HC II were removed from plasma by treatment with an equal volume of a $50 \mathrm{~g} /$ liter bentonite suspension. After centrifugation at $1,700 \mathrm{~g}$ for $15 \mathrm{~min}$, the supernatant was collected and a $100-\mu \mathrm{l}$ sample brought to $37^{\circ} \mathrm{C}$. Bovine HC II, $100 \mu \mathrm{l}(\sim 0.26 \mathrm{U} / \mathrm{ml})$ was added and incubated at $37^{\circ} \mathrm{C}$ for $2 \mathrm{~min}$. Thrombin, $100 \mu \mathrm{l}(6 \mathrm{NIH}$ $\mathrm{U} / \mathrm{ml}$ ), was added and incubated for a further $2 \mathrm{~min}$. The synthetic thrombin substrate CBS 34.47, $100 \mu \mathrm{l}$ (H-D-cyclohexyl-Gly-But-ArgpNA, $0.16 \mu \mathrm{mol} / \mathrm{ml}$ ), was added and incubated for $1 \mathrm{~min}$. The reaction was stopped with $100 \mu \mathrm{l}$ of $50 \%$ acetic acid and the absorbance was read at $405 \mathrm{~nm}$. This was compared to a standard curve generated using normal adult plasma to which varying amounts of porcine mucosal DS had been added before bentonite treatment. Pooled normal adult plasma had no measurable baseline activity since treatment with chondroitin $\mathrm{ABC}$ lyase did not result in a decrease in thrombin inhibition (i.e., increased absorbance at $405 \mathrm{~nm}$ ). Assay of purified material was identical except that the standard curve was generated by adding varying amounts of porcine mucosal DS to $0.15 \mathrm{M} \mathrm{NaCl}$ and the bentonite step was eliminated. All positive results were confirmed by reaction of bentonite-treated plasma with chondroitin $\mathrm{ABC}$ lyase (final concentration $0.33 \mathrm{U} / \mathrm{ml}$ ) for $1 \mathrm{~h}$ at $37^{\circ} \mathrm{C}$ before assay. This was to confirm that any activity present was due to DS rather than heparin or heparan sulfate, since these are also active in this assay system.

This system was inaccurate in cord plasma as some substance (possibly bilirubin) appeared to interfere with absorbance readings at 405 $\mathrm{nm}$. Partial purification of GAG-containing substances from cord plasma was carried out by partial protease digestion with Pronase E (final concentration $2.5 \mathrm{mg} / \mathrm{ml}$ ) at $45^{\circ} \mathrm{C}$ for $4 \mathrm{~h}$. To this was added $2 \mathrm{vol}$ of $3 \mathrm{M} \mathrm{NaCl}$ followed by acidification with $1 / 20$ vol of $3 \mathrm{M}$ acetic acid. The mixture was boiled for $5 \mathrm{~min}$ then put on ice. Precipitate was removed by centrifugation at $30,000 \mathrm{~g}$ for $20 \mathrm{~min}$ at $10^{\circ} \mathrm{C}$. The supernatant was mixed with $3 \mathrm{vol}$ of cold $\left(4^{\circ} \mathrm{C}\right)$ ethanol $/ 0.0058 \mathrm{M}$ sodium acetate and mixed vigorously. The material was left at $4^{\circ} \mathrm{C}$ until centrifugation at $5,000 \mathrm{~g}$ for $20 \mathrm{~min}$ at $4^{\circ} \mathrm{C}$. The supernatant was removed and the pellet resuspended in one-half supernatant volume of $0.015 \%$ cetylpyridinium chloride $/ 0.02 \mathrm{M} \mathrm{NaCl}$ at $37^{\circ} \mathrm{C}$ with vigorous mixing. This was kept at $4^{\circ} \mathrm{C}$ for $18 \mathrm{~h}$ and then the precipitated cetylpyridinium chloride was redissolved by warming to room temperature. The material was centrifuged as above but at room temperature and the supernatant removed. The pellet was resuspended in $1 \mathrm{ml}$ of $3 \mathrm{M} \mathrm{NaCl}$ and passed through a Hyflo Super-Cel column $(0.6 \times 1.3 \mathrm{~cm})$ equilibrated with $3 \mathrm{M} \mathrm{NaCl}$ at $45^{\circ} \mathrm{C}$. The column was washed with $3 \mathrm{ml}$ of $3 \mathrm{M}$ $\mathrm{NaCl}$ and the eluate combined with $8 \mathrm{ml}$ of water. Cold ethanol/ $0.0058 \%$ sodium acetate, $36 \mathrm{ml}$, was added to this fraction and kept at $4^{\circ} \mathrm{C}$ for $18 \mathrm{~h}$. This was centrifuged as above, the supernatant removed, and the pellet freeze dried. The pellet was resuspended in $0.3 \mathrm{ml}$ of water for analysis. The yield of the procedure was monitored by assay of the mass of ACase-resistant/ABCase-sensitive GAG present before and after the purification in both cord and adult plasmas and was somewhat variable ranging from $15 \%$ to $60 \%$. 
Purification and characterization of plasma DS. In that it was possible that the plasma DS was present as a proteoglycan, the above procedure was modified to preserve proteins. Pooled plasmas were mixed with $2 / 3$ vol of saturated ammonium sulfate and stirred at $23^{\circ} \mathrm{C}$ for $1 \mathrm{~h}$. This mixture was centrifuged at $4,000 \mathrm{~g}$ for $15 \mathrm{~min}$ and the supernatant was dialyzed against $0.15 \mathrm{M} \mathrm{NaCl}$. This material was warmed to $37^{\circ} \mathrm{C}$ and mixed thoroughly with $10 \%$ cetylpyridinium chloride to a final concentration of $1 \%$ and kept at $4^{\circ} \mathrm{C}$ overnight. The precipitated cetylpyridinium chloride was redissolved by warming to $20^{\circ} \mathrm{C}$. The material was then centrifuged at $23^{\circ} \mathrm{C}$ at $4,000 \mathrm{~g}$ for $20 \mathrm{~min}$ and the supernatant was removed. The pellet was resuspended in one-fifth original plasma volume of $3 \mathrm{M} \mathrm{NaCl}$ at $45^{\circ} \mathrm{C}$ and three-fifths original plasma volume of cold ethanol $/ 0.0058 \mathrm{M}$ sodium acetate was quickly added. The mixture was kept at $4^{\circ} \mathrm{C}$ overnight then centrifuged at $4,000 \mathrm{~g}$ for $20 \mathrm{~min}$ at $4^{\circ} \mathrm{C}$. The supernatant was removed and the pellet resuspended in onefifth original plasma volume of water and again precipitated with threefifths original plasma volume of cold ethanol/sodium acetate. This was centrifuged at $4,000 \mathrm{~g}$ for $20 \mathrm{~min}$ at $4^{\circ} \mathrm{C}$. The pellet was freeze-dried and resuspended in $1 \mathrm{ml}$ of $1 \mathrm{M} \mathrm{NaCl}$. After centrifugation in an Eppendorf centrifuge, the supernatant was collected and the pellet washed with a small volume of $1 \mathrm{M} \mathrm{NaCl}$. The supernatant and washings were dialyzed against $0.15 \mathrm{M} \mathrm{NaCl}$ and assayed for DS anticoagulant activity. The yield of anticoagulant active DS from this procedure was $40-70 \%$.

The isolated material was subjected to gel chromatography on Sepharose CL-4B $(1.0 \times 49 \mathrm{~cm})$ in $1 \mathrm{M} \mathrm{NaCl}$. Fractions of $1.2 \mathrm{ml}$ were collected and consecutive fractions were pooled in groups of two, freeze-dried, reconstituted in $0.5 \mathrm{ml}$ of water, dialyzed against $0.15 \mathrm{M}$ $\mathrm{NaCl}$, and assayed for DS anticoagulant activity. Purified material was also subjected to reductive elimination by reaction of $0.5 \mathrm{ml}$ of material with $0.055 \mathrm{ml} 2 \mathrm{M} \mathrm{KOH}$ for $3 \mathrm{~h}$ at $23^{\circ} \mathrm{C}$, and then $0.1 \mathrm{ml}$ of $200 \mu \mathrm{M}$ $\mathrm{NaBH}_{4} / 0.1 \mathrm{M} \mathrm{NaOH}$ was added and incubated for a further $17 \mathrm{~h}$. This was neutralized with $14 \mu \mathrm{l}$ of $50 \%$ acetic acid. The product was subjected to gel chromatography on Sephadex G-200 $(1.0 \times 49 \mathrm{~cm})$ in $1 \mathrm{M}$ $\mathrm{NaCl}$. Fractions of $1.2 \mathrm{ml}$ were collected, and consecutive fractions were pooled in groups of three and freeze-dried, reconstituted in $0.5 \mathrm{ml}$ of water, dialyzed against $0.15 \mathrm{M} \mathrm{NaCl}$, and assayed for DS anticoagulant activity. Dextrans or dextran sulfates of known average molecular weight were used as standards on both columns to estimate molecular weight. In addition, purified material was added to normal adult plasma to achieve an activity level equivalent to $0.4 \mu \mathrm{g}$ of porcine mucosal DS/ml. Thrombin-inhibitor complex formation in this mixture was measured as above.

Statistics. Groups were compared using a paired (for pre- and postdelivery samples) or unpaired one-sided $t$ test with $P<0.05$ considered significant.

\section{Results}

Thrombin-inhibitor complex formation. The concentration of thrombin-HC II complexes (Fig. 1) was higher in the plasmas of pregnant women before delivery $(3.0 \pm 0.7 \mathrm{nM}$, mean $\pm \mathrm{SD})$ than $3-5 \mathrm{~d}$ postpartum $(1.9 \pm 0.5 \mathrm{nM}, P<0.01)$. The latter plasma was similar to pooled adult plasma $(1.5 \pm 0.4 \mathrm{nM})$. The amounts of thrombin bound to other inhibitors are shown in Table I.

The simplest explanation for this observation would be a change in HC II levels. However, the HC II level in this group of women was $1.35 \pm 0.09 \mathrm{U} / \mathrm{ml}$ (mean \pm SEM) predelivery compared with $1.16 \pm 0.07 \mathrm{U} / \mathrm{ml}(P>0.05)$ postdelivery. In the nonpregnant adult pool, the level was $0.90 \pm 0.06 \mathrm{U} / \mathrm{ml}$. Thus, a difference in HC II levels did not completely account for the observed increase in thrombin inhibition. We hypothesized that there was some other substance present in pregnancy plasma which catalyzed the thrombin-HC II interaction. In
Figure 1. Autoradiograms of thrombin-inhibitor complexes. Approximately 10,000 cpm per lane was loaded. Lane $A$, thrombin alone; lane $B$, predelivery plasma; lane $C$, 3 d postpartum plasma; lane $D$, nonpregnant adult plasma (from a different run). Labeled bands are thrombin$\alpha_{2} \mathrm{M}(1 a, 1 b)$, thrombin-HC II (2), thrombin-AT III (3), uncomplexed $\alpha$-thrombin (4). The bands below $\alpha$ thrombin are $\beta$-thrombin and a small degradation product.

cord plasma, low levels of HC II made this assay too insensitive to detect significant differences in binding of thrombin to HC II.

DS assays. By assay of the mass of DS present in plasma, it was found that pooled pregnancy plasma contained $0.58 \pm 0.02$ $\mu \mathrm{g} / \mathrm{ml}($ mean $\pm \mathrm{SEM})$, cord plasma $0.67 \pm 0.03 \mu \mathrm{g} / \mathrm{ml}$, and normal adult plasma $0.38 \pm 0.05 \mu \mathrm{g} / \mathrm{ml}$ of DS (Table II). Plasma pooled from eight pregnant women at term contained DS anticoagulant activity equivalent to $0.23 \pm 0.02 \mu \mathrm{g}$ (mean $\pm \mathrm{SEM}$ ) of porcine mucosal DS $/ \mathrm{ml}$ of plasma. This activity was abolished by treatment with ABCase but not ACase or enzyme buffer. No activity was detectable in pooled nonpregnant adult plasmas or in plasmas pooled from women on oral contraceptive pills and women at 6,16 , and $30 \mathrm{wk}$ of gestation.

Subsequently, individual anticoagulant assays on 10 pregnant women at term and 10 women $3 \mathrm{~d}$ postpartum were performed. These showed that all pregnant women had measurable activity $(0.19 \pm 0.1 \mu \mathrm{g} / \mathrm{ml}$, mean $\pm \mathrm{SD})$. Postpartum plasmas demonstrated lower levels $(0.09 \pm 0.09 \mu \mathrm{g} / \mathrm{ml}, P<0.01)$ with 4 of the 10 plasmas having no detectable activity. Activity

Table I. Concentration of Thrombin-Inhibitor Complexes in Pregnant and Nonpregnant Patients after In Vitro Addition of ${ }^{125}$-Thrombin

\begin{tabular}{lcccc}
\hline & & AT III & HC II & $\alpha_{2} \mathrm{M}$ \\
\hline & & & $n M$ & \\
Predelivery & $(n=17)$ & $10.2 \pm 1.2$ & $3.0 \pm 0.7$ & $3.7 \pm 0.8$ \\
$\begin{array}{l}\text { Postpartum } \\
\text { Nonpregnant }\end{array}$ & $(n=17)$ & $11.9 \pm 1.0$ & $1.9 \pm 0.5^{*}$ & $3.3 \pm 0.8$ \\
$\quad$ adults & $(n=16)$ & $11.9 \pm 1.2$ & $1.5 \pm 0.4^{*}$ & $2.7 \pm 1.2$
\end{tabular}

Thrombin-inhibitor complex concentration after reaction of ${ }^{125} \mathrm{I}$ thrombin with plasma (final concentration $25 \mathrm{nM}$ ) for $90 \mathrm{~s}$. Quantitation was performed using scanning densitometry after SDS-PAGE of the plasma/thrombin mixture and autoradiography. Concentration is expressed as mean $\pm \mathrm{SD}$.

* Significantly different from predelivery value $(P<0.05)$. 


\begin{tabular}{lccc}
\hline & $\begin{array}{c}\text { Anticoagulant } \\
\text { activity }\end{array}$ & Mass & $\begin{array}{c}\text { Mass difference } \\
\text { (from normal pool) }\end{array}$ \\
\hline & & $\mu g / m l$ & \\
Pregnancy pool & $0.23 \pm 0.02$ & $0.58 \pm 0.02^{*}$ & 0.20 \\
Cord pool & $(0.20)$ & $0.67 \pm 0.03^{*}$ & 0.29 \\
Normal pool & $0(0.03)$ & $0.38 \pm 0.05$ & - \\
& & &
\end{tabular}

Summary of anticoagulant activity and mass assays for DS in cord and pregnancy plasma. Anticoagulant activity is based on a chromogenic, HC II-dependent antithrombin assay. Mass assay is based on alcian blue $8 \mathrm{GX}$ binding to glycosaminoglycan resistant to degradation by chondroitin AC lyase but sensitive to chondroitin $\mathrm{ABC}$ lyase. Values for activity and mass are expressed as mean \pm SEM or estimates of activity (in parentheses) based on yield and activity of purified material.

* Significantly different from normal pool $(P<0.05)$.

was abolished in all cases by $\mathrm{ABCase}$ but not $\mathrm{ACase}$. In comparison, activity was not measurable in 10 nonpregnant adults.

DS activity could not be accurately measured in cord plasma as some fraction in the plasma (likely bilirubin) interfered with absorbance readings at $405 \mathrm{~nm}$. Therefore, partial purification was undertaken of cord and nonpregnant adult pooled plasmas. When corrected for yield (determined by mass assay), the DS activity in cord plasma was $\sim 0.2 \mu \mathrm{g} / \mathrm{ml}$. As noted above, no DS activity was detected in plasma from nonpregnant adults. Following the same purification technique used for cord plasma, activity was detected in the concentrate of nonpregnant adult plasma which, when corrected for yield, was $0.03 \mu \mathrm{g} / \mathrm{ml}$ in the original plasma. This is below the sensitivity of the DS anticoagulant activity assay in a plasma system.

Characterization of plasma DS. Gel chromatography of material isolated from both pregnancy and cord plasmas on Sepharose CL-4B yielded similar results. A single, somewhat polydisperse peak of anticoagulant activity was seen with a $K_{\mathrm{av}}$ of 0.67 (Fig. 2). After reductive elimination, chromatography on Sephadex G-200 was again similar and demonstrated a peak with $K_{\text {av }}$ of 0.54 for pregnancy and 0.40 for cord.

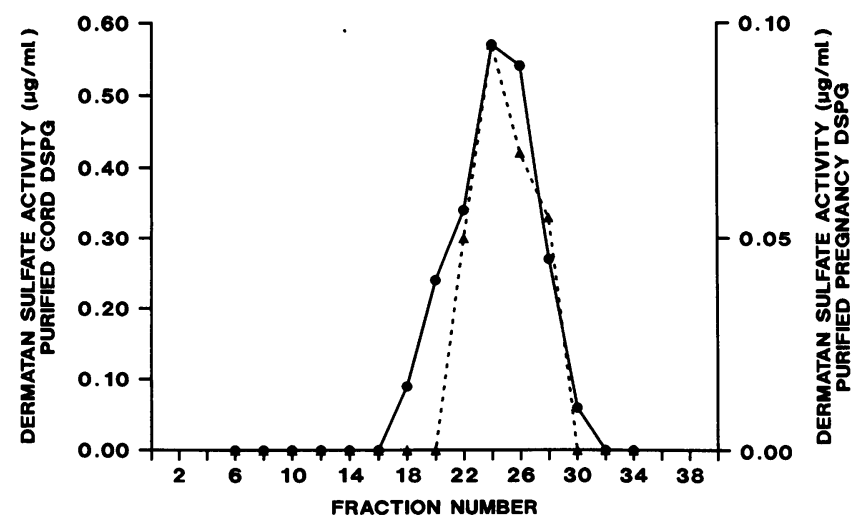

Figure 2. DS activity of purified GAG-containing material from cord $(\bullet)$ and pregnancy $(\triangle)$ plasma after gel chromatography on Sepharose CL-4B. Void volume is fraction 11; column volume is fraction 33 . Note different $y$-axis scales.
After addition of material isolated from pregnancy plasma, thrombin complexes with HC II were increased over nonpregnant adult control and decreased to baseline with chondroitin $\mathrm{ABC}$ lyase treatment but not chondroitin AC lyase. Similarly, when material isolated from cord plasma was added to adult plasma, increased HC II-thrombin complexes were noted which decreased to baseline with chondroitin $\mathrm{ABC}$ lyase but not chondroitin AC lyase (data not shown).

\section{Discussion}

There are profound changes in the hemostatic system during normal pregnancy that lead to thrombin generation, fibrin deposition, and fibrinolysis within the placenta or at the uteroplacental junction $(10-12,25,26)$. Localized fibrin deposition is important for the establishment and possibly repair of the placenta $(27,28)$. However, uncontrolled thrombin generation in the uteroplacental unit could lead to systemic thrombosis, particularly in the late stages of pregnancy when there is marked impairment of deep venous blood flow.

We have noted an increase in thrombin inhibition by HC II in plasmas from pregnant women at term. Though these women had slightly increased levels of HC II, consistent with previous reports $(6,7)$, this was insufficient to completely account for the observation since postpartum HC II concentrations were not significantly different from antepartum yet, postpartum there was less contribution of HC II to thrombin complex formation. We hypothesized that a substance was present which catalyzed the thrombin-HC II reaction. This was confirmed in a HC II-dependent antithrombin assay in both pregnancy plasma and in partially purified material from cord plasma.

Several GAGs are capable of catalyzing the thrombin-HC II reaction including heparin, heparan sulfate, DS, and very high levels of chondroitin-4-sulfate and chondroitin-6-sulfate (29). None of the subjects had received heparin. In the plasmas from pregnant women, thrombin inhibition by AT III was not increased, thus, endogenous heparan sulfate could not be the catalyzing substance since it primarily catalyzes thrombin-AT III formation. The catalyzing activity was abolished by ABCase, but not ACase, in all instances. Thus, this activity was attributable to DS rather than chondroitin-4- or -6-sulfate.

The presence of DS in the plasma of healthy adults has been shown previously (30). Extrapolating from the total GAG content of serum (31), the amount of DS expected would be $\sim 0.20-0.25 \mu \mathrm{g} / \mathrm{mL}$. The value for adult pooled plasma by our mass assay method is in reasonable agreement with these reports. However, the DS normally present in adult plasma had little catalytic activity. In contrast, the increment in total DS mass in pregnancy and cord plasma over adult plasma agrees well with the measured activity. It appears that most of the increase in DS mass is anticoagulant active DS.

Purification of GAG containing material from pregnancy and cord plasmas revealed that the active DS present was similar in both. The $K_{\mathrm{av}}$ on Sepharose CL-4B corresponds to an average $M_{\mathrm{r}}$ of $150,000 \mathrm{D}$. This is much larger than typical DS GAG chains, suggesting that the substance was a proteoglycan rather than free GAG. This was confirmed by the decrease in $M_{\mathrm{r}}$ of the active fraction after reductive elimination which cleaves the O-linked GAG chains from the core protein of a proteoglycan. 
Thus, we have identified a DS proteoglycan in the plasmas of pregnant women obtained immediately before delivery and in cord blood at delivery. This DS proteoglycan is capable of catalyzing the inhibition of thrombin by HC II. We were unable to detect this material in plasmas from healthy nonpregnant adults, women on oral contraceptive pills, or pregnant women at up to $30 \mathrm{wk}$ of gestation. We have not yet studied in detail the period from $30 \mathrm{wk}$ of gestation to term to determine when this first appears.

DS proteoglycans are a family of proteoglycans which are ubiquitous in the extracellular matrix of connective tissue (32) and serve multiple functions (33). During pregnancy, the placenta (34) and uterus (35) are rich in DS proteoglycan. The mechanism by which this DS proteoglycan might appear in blood is unknown. The rapid decrease in activity postpartum suggests that this is an effect of pregnancy and that the activity may be of placental origin. The source of the DS proteoglycan in the fetus is also speculative. However, we have previously shown, in an animal model, that DS-like activity is found in the fetal circulation after administration of a low-molecular weight heparin (36) to the mother, indicating that there is a pool of DS which can be released into the fetal circulation.

Anticoagulant activity has been previously isolated from the placenta $(37,38)$ and from cord blood (39). The anticoagulant activity from placenta was shown to be secondary to a protein which binds phospholipid and does not inhibit thrombin $(37,40)$, clearly distinguishing it from the substance we have isolated. In addition, it has not been shown to circulate in the blood. The activity isolated from cord blood demonstrated "heparin-like" thrombin inhibition. Further characterization showed that it did not act through AT III (41) and the original observation was attributed, in part, to a fetal fibrinogen. This may have also represented DS activity which would not have been appreciated since the presence of HC II was not known at that time. Circulating anticoagulant GAG molecules have been noted in some pathologic conditions (42-45). To our knowledge, this is the first demonstration of this phenomenon in physiologic states.

The ability of DS to enhance thrombin inhibition by HC II has only recently been described (46). It has led to the investigation of DS as an antithrombotic agent (47-50) in animal models. These have shown it to be effective with less bleeding side effects than heparin. Thus, the finding of an active DS proteoglycan in pregnancy and in cord blood of newborn infants is of interest. Its presence may partly explain the low risk of thrombosis in pregnant women and fetuses when there is increased thrombin generation. Because it falls rapidly after delivery, it might also provide an explanation for the increased incidence of thrombosis in the puerperium. Further studies on the site of origin, time course of appearance, and physiological relevance of the measured levels are needed to clarify its role.

\section{Acknowledgments}

The authors acknowledge the staffs of the Coagulation Laboratory and Labour and Delivery Unit, St. Joseph's Hospital, Hamilton, Ontario for sample collection and processing and Dr. M. W. C. Hatton for reviewing the manuscript.

This work was supported by a grant from Physicians Services Incorporated and the Medical Research Council of Canada. Dr. Andrew is a
Career Scientist of the Heart and Stroke Foundation of Ontario. Dr. Delorme is a Research Fellow of the Heart and Stroke Foundation of Canada.

\section{References}

1. Stirling, Y., L. Woolf, W. R. S. North, M. J. Seghatchian, and T. W. Meade 1984. Haemostasis in normal pregnancy. Thromb. Haemostasis. 52:176-182.

2. Kruithof, E. K. O., C. Tran-Thang, A. Gudinchet, J. Hauert, G. Nicoloso, C. Genton, H. Welf, and F. Bachmann. 1987. Fibrinolysis in pregnancy: a study of plasminogen activator inhibitors. Blood. 69:460-466.

3. Wright, J. G., P. Cooper, B. Astedt, I. Lecander, J. T. Wilde, F. E. Preston, and $M$. Greaves. 1988. Fibrinolysis during normal human pregnancy: complex interrelationship between plasma levels of tissue plasminogen activator and inhibitors and the euglobulin clot lysis time. Br. J. Haematol. 69:253-258.

4. Dalaker, K., and H. Prydz. 1984. The coagulation factor VII in pregnancy. Br. J. Haematol. 56:233-241.

5. Weiner, C. P., and J. Brandt. 1980. Plasma antithrombin III activity in normal pregnancy. Obstet. Gynecol. 56:601-603.

6. Ezenagu, L. C., and J. T. Brandt. 1986. Laboratory determination of heparin cofactor II. Arch. Pathol. Lab. Med. 110:1149-1151.

7. Massouh, M., A. Jatoi, E. M. Gordon, and O. D. Ratnoff. 1989. Heparin cofactor II activity in plasma during pregnancy and oral contraceptive use. $J$. Lab. Clin. Med. 114:679-699.

8. Mannucci, P. M., S. Vigano, B. Bottasso, G. Candotti, P. Bozetti, E. Rossi, and G. Pardi. 1984. Protein $C$ antigen during pregnancy, delivery and puerperium. Thromb. Haemostasis. 52:217.

9. Comp, P. C., G. R. Thurnau, J. Welsh, and C. T. Esmon. 1986. Functiona and immunologic protein $S$ are decreased during pregnancy. Blood. 68:881-885.

10. de Boer, K., J. W. ten Cate, A. Sturk, J. J. J. Borm, and P. E. Treffers 1989. Enhanced thrombin generation in normal and hypertensive pregnancy. Am. J. Obstet. Gynecol. 160:95-100.

11. Weiner, C. P., H. Kwaan, W. W. Hauck, F. J. Duboe, M. Paul, and C.-B. Wallemark. 1984. Fibrin generation in normal pregnancy. Obstet. Gynecol. 64:46-48.

12. Pinto, S., R. Abbate, C. Rostagno, V. Bruni, D. Rosati, and G. G. Neri Serneri. 1988. Increased thrombin generation in normal pregnancy. Acta Eur. Fertil. 19:263-267.

13. Ofosu, F. A., P Sie, G. J. Modi, F. Fernandez, M. R. Buchanan, M. A. Blajchman, B. Boneu, and J. Hirsh. 1987. The inhibition of thrombin-dependent positive-feedback reactions is critical to the expression of the anticoagulant effect of heparin. Biochem. J. 243:579-588.

14. Henderson, S. R., C. J. Lund, and W. T. Creasman. 1972. Antepartum pulmonary embolism. Am. J. Obstet. Gynecol. 112:476-483.

15. Aaro, L. A., and J. L. Juergens. 1974. Thrombophlebitis and pulmonary embolism as complications of pregnancy. Med. Clin. N. Am. 58:829-834.

16. Kerr, M. G., D. B. Scott, and E. Samuel. 1964. Studies of the inferior vena cava in late pregnancy. Br. Med. J. 1:532-533.

17. Carter, C., M. Gent, and J. R. Leclerc. 1987. The epidemiology of venous thrombosis. In Hemostasis and Thrombosis: Basic Principles and Clinical Practice. R. W. Colman, J. Hirsh, V. J. Marder, and E. W. Salzman, editors. J. B. Lippincott Co., Toronto. 1190

18. Andrew, M., B. Paes, R. Milner, M. Johnston, L. Mitchell, D. M. Tollefson, and P. Powers. 1987. Development of the human coagulation system in the full-term infant. Blood. 70:165-172.

19. Yuen, P. M. P., J. A. Yin, and T. T. H. Lao. 1989. Fibrinopeptide A levels in maternal and newborn plasma. Eur. J. Obstet. Gyn. Rep. Biol. 30:239-244.

20. Marler, R. A., R. R. Montgomery, and A. W. Broekmans. 1989. Diagnosis and treatment of homozygous protein C deficiency. J. Pediatr. 114:528-534.

21. Schmidt, B., L. Mitchell, F. A. Ofosu, and M. Andrew. 1989. Alpha-2-macroglobulin is an important progressive inhibitor of thrombin in neonatal and infant plasma. Thromb. Haemostasis. 62:1074-1077.

22. van der Heiden, R., M. W. C. Hatton, and S. Moore. 1988. Extraction and analysis of glycosaminoglycans from intima-media of single rabbit aortae: effect of balloon catheter de-endothelialization on the content and profile of glycosaminoglycans. Atherosclerosis. 73:203-213.

23. Bartold, P. M., and R. C. Page. 1985. A micro determination method for assaying glycosaminoglycans and proteoglycans. Ann. Biochem. 150:320-324.

24. Dupouy, D., P. Sie, F. Dol, and B. Boneu. 1988. A simple method to measure dermatan sulfate at sub-microgram concentrations in plasma. Thromb. Haemostasis. 60:236-239.

25. McKillop, C., C. D. Forbes, P. W. Howie, and C. R. M. Prentice. 1976. Soluble fibrinogen/fibrin complexes in pre-eclampsia. Lancet. $i:$ 56-58.

26. Ballegeer, V., P. Mombaerts, P. J. Declerk, B. Spitz, F. A. Van Assche, and D. Collen. 1987. Fibrinolytic response to venous occlusion on fragment D-dimer levels in normal and complicated pregnancy. Thromb. Haemostasis. 58:10301032 
27. Bonnar, J., and B. L. Sheppard. 1977. The vascular supply of the placenta in normal and abnormal pregnancy. In Pathology of the Female Genital Tract. A. Blaustein, editor. Springer-Verlag, Inc., New York. 673-689.

28. Nelson, D. M., E. C. Crouch, E. M. Curran, and D. R. Farmer. 1990. Trophoblast interaction with fibrin matrix: epithelialization of perivillous fibrin deposits as a mechanism for villous repair in the human placenta. Am. J. Pathol. 136:855-856.

29. Fernandez, F. A., M. R. Buchanan, J. Hirsh, J. W. Fenton II, and F. A. Ofosu. 1987. Catalysis of thrombin inhibition provides an index for estimating the antithrombotic potential of glycosaminoglycans in rabbits. Thromb. Haemostasis. 57:286-293.

30. Murata K., and Y. Horiuchi. 1977. Molecular weight dependent distribution of acidic glycosaminoglycans in human plasma. Clin. Chim. Acta. 75:59-69.

31. Mitra, S. K., and K. Blau. 1978. An improved determination of total glycosaminoglycans in body fluids by formation of complexes with quinacrine: changes in amniotic fluid total glycosaminoglycans during normal pregnancy and in pregnancies at risk for mucopolysaccharidosis. Clin. Chim. Acta. 89:127-134.

32. Heinegård, D., A. Björne-Persson, L. Cöster, A. Franzén, S. Gardell, A Malmström, M. Paulsson, R. Sundfalk, and K. Vogel. 1985. The core proteins of large and small interstitial proteoglycans from various connective tissues form distinct subgroups. Biochem. J. 230:181-194.

33. Rosenberg, L. C., H. U. Choi, A. R. Poole, K. Lewandowska, L. A. Culp. 1986. Biological roles of dermatan sulfate proteoglycans. In Functions of the Proteoglycans. D. Evered and J. Whelan, editors. John Wiley \& Sons, Toronto. 47-61.

34. Brennan, M. J., A. Oldberg, M. D. Pierschbacher, and E. Ruoslahti. 1984. Chondroitin/dermatan sulfate proteoglycan in human fetal membranes: demonstration of an antigenically similar proteoglycan in fibroblasts. J. Biol. Chem. 259:13742-13750.

35. Uldberg, N., A. Malmström, G. Ekman, J. Sheehan, U. Ulmsten, and L. Wingerup. 1983. Isolation and characterization of the dermatan sulfate proteoglycan from human uterine cervix. Biochem. J. 209:497-503.

36. Andrew, M., F. Ofosu, F. Fernandez, A. Jeffries, J. Hirsh, L. Mitchell, and M. R. Buchanan. 1986. A low molecular weight heparin alters the fetal coagulation system in the pregnant sheep. Thromb. Haemostasis. 55:342-346.

37. Funakoshi, T., R. L. Heimark, L. E. Hendrickson, B. A. McMullen, and K. Fujikawa. 1987. Human placental anticoagulant: isolation and characterization. Biochemistry. 26:5572-5578.
38. Iwasaki, A., M. Suda, H. Nakao, T. Nagoya, Y. Saino, K. Arai, T. Mizoguchi, F. Sato, H. Yoshizaki, M. Hirata, et al. 1987. Structure and expression of cDNA for an inhibitor of blood coagulation isolated from human placenta: a new lipocortin-like protein. J. Biochem. 102:1261-1273.

39. Muller, A. D., J. M. van Doorm, and H. C. Hemker. 1976. Heparin-like inhibitor of blood coagulation in normal newborn. Nature (Lond.). 267:793-794.

40. Kondo, S., M. Noguchi, T. Funakoshi, K. Fujikawa, and W. Kisiel. 1987. Inhibition of human factor VIIa-tissue factor activity by placental anticoagulant protein. Thromb. Res. 48:449-459.

41. Kirchhof, B. R. J., A. D. Muller, and H. C. Hemker. 1979. An inhibitor of clot formation in cord plasma. Thromb. Res. 15:389-403.

42. Khoory, M. S., M. E. Nesheim, E. J. W. Bowie, and K. G. Mann. 1980 Circulating heparan sulfate proteoglycan anticoagulant from a patient with a plasma cell disorder. J. Clin. Invest. 65:666-674.

43. de Prost, D., C. Katlama, G. Pialoux, F. Karsenty-Mathonnet, and M. Wolff. 1987. Heparin-like anticoagulant associated with AIDS. Thromb. Haemostasis. 57:239.

44. Horne, M. K., C. A. Stein, R. V. Larocca, and C. E. Myers. 1988. Circulating glycosaminoglycan anticoagulants associated with suramin treatment. Blood. 71:273-279.

45. Tefferi, A., B. A. Owen, W. L. Nichols, T. E. Witzig, and W. G. Owen. 1989. Isolation of a heparin-like inhibitor of blood coagulation from the plasma of a patient with metastatic bladder carcinoma. Blood. 74:252-254.

46. Tollefson, D. M., C. A. Pestka, and W. J. Monafo. 1983. Activation of heparin cofactor II by dermatan sulfate. J. Biol. Chem. 258:6713-6716.

47. Fernandez, F., J. Van Ryn, F. A. Ofosu, J. Hirsh, and M. R. Buchanan. 1986. The haemorrhagic and antithrombotic effects of dermatan sulfate. Br. J. Haematol. 64:309-317.

48. Merton, R. E., and D. P. Thomas. 1987. Experimental studies on the relative efficacy of dermatan sulfate and heparin as antithrombotic agents. Thromb. Haemostasis. 58:839-842.

49. Maggi, A., M. Abbadini, P. G. Pagella, A. Borowska, J. Pangrazzi, and M. B. Donati. 1987. Antithrombotic properties of dermatan sulfate in a rat venous thrombosis model. Haemostasis. 17:329-335.

50. Hoppensteadt, D., A. Racanelli, J. M. Walenga, and J. Fareed. 1989. Comparative antithrombotic and hemorrhagic effects of dermatan sulfate, heparan sulfate and heparin. Semin. Thromb. Hemostasis. 15:378-385. 